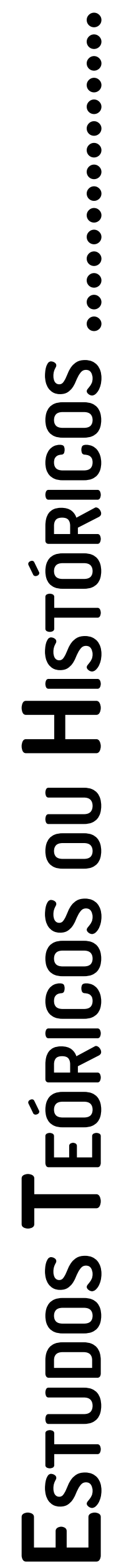




\section{GÊNERO COMO MODALIDADE EXISTENCIAL}

Resumo: As discussões de gênero são ainda fundamentais para as lutas (trans)feministas e possuem um campo aberto a novas reflexões que contribuam no tema. Essa questão é cara à fenomenologia desde Simone de Beauvoir até Judith Butler e outras fenomenólogas feministas contemporâneas. Considerando as contribuições já desveladas por essas autoras, este trabalho possui o objetivo de repensar a conceituação de gênero por meio do conceito de modalidade existencial encontrado em Merleau-Ponty e Heidegger em uma revisão teórica assistemática. O conceito de modalidade existencial implica em possibilidades, como fundamental na estrutura ontológica do ser. Possibilidade tem aqui características existenciais e de abertura que descrevem modos de ser, de se vincular, significar e tornar possível ser e sentido. O gênero como modalidade existencial desvela um espectro de potências que se realiza e se institui na existência corpórea e situada do ser. Este trabalho possibilita um diálogo com as reflexões já realizadas pelas autoras feministas e a abertura para o aprofundamento das discussões sobre gênero.

Palavras-chave: Gênero; Modalidade Existencial; Fenomenologia.

Abstract: Gender discussions are still fundamental to (trans)feminist struggles and have an open field to new reflections that contribute to the topic. This issue is important to phenomenology from Simone de Beauvoir to Judith Butler and other contemporary feminist phenomenologists. Considering the contributions already unveiled by these authors, this paper aims to rethink the conceptualization of gender through the concept of existential modality found in MerleauPonty and Heidegger in a non-systematic theoretical review. The concept of existential modality implies possibilities as fundamental in the ontological structure of being. Here, possibility has existential and open characteristics that describe ways of being, of linking, meaning and make possible being and meaning. Gender as an existential modality reveals a spectrum of potencies that is realized and established in the corporeal and situated existence of being. This work allows a dialogue with the reflections already made by the feminist authors and the opening to deepen the discussions about gender.

Keywords: Gender; Existential Modality; Phenomenology.

Resumen: Las discusiones de género siguen siendo fundamentales para las luchas (trans)feministas y tienen un campo abierto a nuevas reflexiones que contribuyen al tema. Este tema es apreciado por la fenomenología desde Simone de Beauvoir hasta Judith Butler y otras fenomenólogas feministas contemporáneas. Teniendo en cuenta las contribuciones ya presentadas por estas autoras, este artículo tiene como objetivo repensar la conceptualización del género a través del concepto de modalidad existencial que se encuentra en Merleau-Ponty y Heidegger en una revisión teórica no sistemática. El concepto de modalidad existencial implica posibilidades como fundamentales en la estructura ontológica del ser. La posibilidad aquí tiene características existenciales y abiertas que describen formas de ser, de vinculación, significado y hacer posible ser y sentido. El género como modalidad existencial revela un espectro de potencias que se realiza y establece en la existencia corporal y situada del ser. Este trabajo permite un diálogo con las reflexiones ya hechas por las autoras feministas y la apertura para profundizar las discusiones sobre género.

Palabras-clave: Género; Modalidad Existencial; Fenomenología.

\section{Introdução}

A definição do conceito de gênero é um campo de complexas disputas históricas que são marcadas de lutas por direitos humanos, políticos, econômicos, culturais e étnicos. Esses movimentos que discutiram a categorização de gênero, suas relações e implicações, iniciaram-se na luta das mulheres negras escravas, das mulheres brancas e burguesas e, mais recentemente, continuam a se delinear novas questões em relação às pessoas transgêneras. Se a utilização deste conceito implica no cotidiano e no direito a existência de toda pessoa, especialmente em relação às mulheres e pessoas trans, como a fenomenologia-existencial pode contribuir para essas discussões?

Em certo momento histórico, essa terminologia definiu categorias baseadas em um ancoramento da noção de gênero nas características genitais e sexuais da pessoa. A esse uso do gênero ancorado na noção biológica de sexo, Sara Heinämaa (2012), filósofa finlandesa, chama de "uso substancial"1. O mesmo

1 Tradução nossa de substantial use. (Heinämaa, 2012) 
se refere ao que Berenice Bento (2008) destaca quando discute o binarismo normativo que delimita apenas duas possibilidades de identidade-gênerosexo: homem-masculino-pênis ou mulher-femininovagina. A limitação desse pensamento é clara quando a realidade de pessoas trans, por exemplo, explicita outras possibilidades de identidade que não se relacionam com a normativa de gênero baseada na área genital e caracteres sexuais secundários.

Outra proposta é a de considerar a questão como sendo uma construção social, de papéis normativos e bem delimitados que caracterizam o ser homem e o ser mulher, o que Heinämaa (2012) aponta como sendo o "uso criterial" ${ }^{2}$ do conceito de gênero. Esse tipo de categorização social cria expectativas de comportamentos e características individuais específicas para cada gênero, de acordo com uma história e cultura que constrói os papeis relacionados ao ser mulher e ao ser homem. De fato, a realidade é que a diversidade cultural em relação a esses comportamentos é tamanha que não comporta justificar que gênero é apenas construído socialmente de um modo universalizante. Pode-se observar com o trabalho de Evelyn Blackwood (2011), sobre a masculinidade contingente de tombois da Indonésia, como o gênero é vivido de modo particular de acordo com uma cultura específica onde se situa o ser.

A questão de gênero também pode envolver modos econômicos e políticos de relações. Segundo Joan Scott (1995), historiadora feminista, gênero vem a ser um "elemento constitutivo de relações sociais baseadas nas diferenças percebidas entre os sexos... uma forma primária de dar significado às relações de poder" (p. 86). Sendo assim, as relações de gênero podem ser (e são) permeadas por complexas estruturas políticas e econômicas que sustentam a hierarquização entre homens e mulheres, subjugando a mulher à dominação masculina. Ainda, convém observar que os "estudos de gênero" passaram a ocupar espaço acadêmico substituindo os "estudos de mulheres", e mesmo os estudos sobre a "diferença sexual", no intuito de galgar certa "neutralidade acadêmica" para as discussões feministas (Scott, 1995). Mas, o sexo, a condição social, histórica e econômica determina o gênero de uma pessoa? Como a fenomenologia tem abordado a questão?

Em O Segundo Sexo vol. II, Simone de Beauvoir (1949/1970a) afirma: "...o fato é que todo ser humano concreto sempre se situa de um modo singular" (p. 8). A filósofa introduz, assim, seu pensamento acerca da situação da mulher no mundo, expondo observações ontológicas sobre a singularidade da existência feminina. Nasce um campo de possibilidades fenomenológicas e existenciais de compreensão do mundo em relação ao gênero.

A posição feminina de Beauvoir (1949/1970a) a coloca em guerra com a hegemonia masculina da filosofia europeia:

2 Tradução nossa de criterial use. (Heinämaa, 2012)
Agastou-me, por vezes, nocurso deconversações abstratas, ouvir os homens dizerem-se: "você pensa assim porque é uma mulher". Mas eu sabia que minha única defesa era responder: "penso-o porque é meu verdadeiro", eliminando assim minha subjetividade... um homem está em seu direito sendo homem, é a mulher que está errada. (p. 9)

No meio de filósofos como Sartre e MerleauPonty, Simone de Beauvoir reconhece sua situação como mulher, entendendo que sua subjetividade deveria ser colocada de lado se fosse para a sua voz e suas ideias serem reconhecidas. Sua obra é hoje reconhecida como um importante marco na história feminista.

Para Beauvoir (1949/1970b), os engendramentos históricos e sociais elaboraram o feminino como um Outro: "ninguém nasce mulher: torna-se mulher" (p. 9). A condição dramática de como essa identidade feminina é apontada posiciona a mulher sob o jugo opressivo do homem. Ser o "segundo sexo" coloca a mulher sob uma alienação corporal, afirmada pelo conjunto cultural e que deteriora sua subjetividade.

Como ela, Iris Marion Young (1980), filósofa estadunidense, descreve aspectos da vivência feminina que destacam três modalidades de corporeidade: uma transcendência ambígua, uma intencionalidade inibida e unidade descontinuada. Um dos pontos centrais de sua discussão é o fato de que a mulher é submetida a uma estrutura social que objetifica seu corpo e faz com que sua experiência corpórea seja não de um corpo, mas de uma coisa, limitada em sua potencialidade, inibida por um conjunto de elementos e relações sociais. Por exemplo, a mulher tende a evitar certos esportes, pois desenvolve seu esquema corporal ouvindo coisas como, "mulher é fraca", "isso não é esporte pra mulher", entre outras falas que limitam o seu desenvolvimento corporal e a potencialidade do seu corpo (Missaggia, 2015). É notável, assim, que a noção de corpo para a fenomenologia contribui para perspectivas profundas sobre as discussões de gênero.

Ao contrário dos conceitos tradicionais de mente e corpo, os conceitos fenomenológicos de consciência e objetividade são mutuamente implicados: a consciência intencional é sempre a consciência de algo, e a objetividade pretendida é sempre válida para alguém. Isso significa que todos os fenômenos corporais envolvem fatores subjetivos e objetivos. Ao diferenciar entre seus tipos e formas, podemos revelar vários aspectos e camadas da corporeidade humana. ${ }^{3}$ (Heinämaa, 2012, p. 22)

3 "Unlike the traditional concepts of mind and body, the phenomenological concepts of consciousness and objectivity are mutually implicatory: intentional consciousness is always consciousness of something, and the intended objectivity is always valid for someone. This means that all bodily phenomena involve both subjective and objective factors. By differentiating between their types and forms, we can disclose several aspects and layers of human embodiment.” (Heinämaa, 2012, p. 22) 
A corporeidade, conceito fenomenológico aprofundado por Merleau-Ponty (1945/2006), impacta no modo como o gênero é compreendido por levar em consideração que o corpo é mais do que objetivo, factual, mas é fenomenal e permeado de ambiguidade: "o corpo é o veículo do ser no mundo, e ter um corpo é, para um ser vivo, juntar-se a um meio definido, confundir-se com certos projetos e empenhar-se continuamente neles” (p. 122). Sendo assim, o gênero não é dado pela factualidade de um genital que normativa e socialmente designa ser mulher ou ser homem. Compreender que o corpo é vivido transcende o binarismo naturalizado.

Essa noção de corpo fenomenológico possibilitou autoras, como Judith Butler, Gayle Salamon e Evelyn Blackwood, descrever e aprofundar experiências transgêneras diversas, abrindo a possibilidade de reconhecimento da verdade dessas existências, retirando-as do estigma patológico. Segundo Salamon (2011), a verdade "não é necessariamente o que vemos, e o binário tradicional da diferença sexual pode ter menos apego à "verdade" do corpo do que outras maneiras de apreender sua realidade vivida" (p. 248). Essa verdade perspectiva, a realidade vivida da pessoa trans em relação ao seu gênero e corpo, é sustentada pela compreensão de corporeidade e percepção merleau-pontyana. Salamon (2011) ainda desenvolve reflexões sobre a função de transposição da sexualidade e o conceito de carne em MerleauPonty de modo a compreender mais profundamente a experiência transgênera. Seus trabalhos, Assuming a Body: Transgender and Rethorics of Materiality e The Life and Death of Latisha King: A Critical Phenomenology of Transphobia, fazem a análise da experiência de corporeidade trans e uma análise crítica de um caso de transfobia que resultou na morte de Latisha King, uma estudante dos Estados Unidos.

Há, ainda, o reconhecido trabalho de Judith Butler, filósofa estadunidense, sobre gênero, performatividade e subversão da identidade, nos livros Gender Trouble: Feminism and the Subversion of Identity e Performative Acts and Gender Constitution: An Essay in Phenomenology And Feminist Theory. Gênero, para Butler (1990/2003), realiza-se nos atos performativos, gestos repetidos ao longo da história e constituídos por um poder social em torno dos corpos. Segundo Butler (1990/2003), "essa repetição é a um só tempo reencenação e nova experiência de um conjunto de significados já estabelecidos socialmente; e também é a forma mundana e ritualizada de sua legitimação" (p. 200). Para ela, o corpo materializa os gestos, constituindo significados e possibilidades diversas, concordando com as argumentações de Merleau-Ponty (1945/2006) e Beauvoir (1949/1970), retratando diálogos fenomenológicos.

4 "is not necessarily what we see, and the traditional binary of sexual difference might have less purchase on the body's "truth" than other ways of apprehending its lived reality." (Salamon, 2011, p. 248)
Aos leitores interessados em outras perspectivas fenomenológicas sobre gênero, existem ainda trabalhos como o de Jacob R. Lau (2018), que realiza uma análise autoetnográfica da sua experiência como pessoa trans e mestiço-asiático, Johanna Oksala (2006), que propõe uma compreensão sobre gênero a que nomeia de pós-fenomenológica, e Bonnie Mann (2018), que tece críticas à fenomenologia feminista. Das autoras clássicas da fenomenologia feminista até os autores contemporâneos que tecem reflexões sobre experiências de gênero diversas, a fenomenologia continua demonstrando ser um campo fecundo para novos aprofundamentos na questão.

Dentre essa diversidade de perspectivas fenomenológicas sobre o gênero, emergem questões que influenciaram o desenvolvimento deste trabalho: se gênero é uma situação engendrada historicamente, onde nessa situação se localizam as pessoas trans? Se é realizado performativamente e vivido de modo ambíguo, como legitimar uma identidade que aparece como subversiva? Se nem corpo e nem história definem a identidade de gênero de uma pessoa, como essa se institui no mundo-vivido do ser? Essas reflexões são fruto do meu processo de pesquisa e mestrado em Psicologia Clínica sobre corporeidade transmasculina e surgiram a partir de uma questão colocada como desafio para mim: "se você está pesquisando transmasculinidade, o que você entende como gênero?”. Assim, esse estudo surgiu de uma revisão assistemática e objetivou propor uma reflexão sobre gênero como modalidade existencial estruturante da relação do ser-no-mundo e a instituição de sua identidade de gênero corporificada. Para responder essa questão, revisaremos a noção de modalidade existencial em Merleau-Ponty e Heidegger para, então, tecer as implicações dessa compreensão fenomenológica na análise sobre gênero e identidade.

\section{Modalidade existencial}

O termo se destaca ao meu olhar, primeiramente, na leitura da obra Fenomenologia da Percepção de Merleau-Ponty (1945/2006). No capítulo O Corpo Como Ser Sexuado, o autor diz o seguinte: "se a cada movimento o corpo exprime as modalidades da existência, veremos que não é como... um número designa uma casa: aqui, o signo não indica apenas sua significação, ele é habitado por ela...” (Merleau-Ponty, $1945 / 2006$, p. 222). Designa aqui a corporeidade e a expressão das modalidades existenciais pelo corpo habitado. De que modalidades trata o autor? Neste capítulo fala sobre a sexualidade, mas ao longo da obra desenvolve outros conceitos que correlaciona com "modalidade existencial" ou "modalidades da existência”.

Desenvolvendo suas reflexões sobre percepção, Merleau-Ponty fala sobre as sensações e o sentir: "Há um sentido em dizer que vejo sons ou que ouço cores, 
se a visão ou a audição não são a simples posse de um quale opaco, mas a experiência de uma modalidade da existência, a sincronização de meu corpo a ela..." (Merleau-Ponty, 1945/2006, p. 314). A compreensão de modalidade existencial em Merleau-Ponty parece, aqui, referir-se a uma experiência vivida por meio de um ato perceptivo, que dá sentidos àquilo que a princípio não teria coerência: posso ouvir cores e enxergar sons. Mais adiante, o autor afirma a sensação como modalidade existencial: "Aquilo que chamamos de sensação é apenas a mais simples das percepções e, enquanto modalidade de existência, ela não pode, assim como nenhuma percepção, separar-se de um fundo que, enfim, é o mundo" (Merleau-Ponty, 1945/2006, p. 324). Neste trecho, o filósofo associa a noção de modalidade existencial com mundo. Assim, uma modalidade da existência é sempre situada e nunca separada do mundo.

Ainda analisando a questão da percepção e do percebido, Merleau-Ponty (1945/2006) afirma que, ambos, “a percepção e o percebido têm necessariamente a mesma modalidade existencial, já que não se poderia separar da percepção a consciência que ela tem, ou, antes, que ela é, de atingir a coisa mesma" (p. 500). Porém, o filósofo aponta para outras modalidades de existência ao longo de sua obra: a imaginação, a fala, o social, o atual e virtual ${ }^{5}$.

No capítulo O Corpo Como Expressão e a Fala, dialogando o ato de fala, o autor equipara a imaginação como modalidade existencial, descrevendo: "Assim como Pedro imaginado é apenas uma das modalidades do meu ser no mundo, a imagem verbal é uma das modalidades de minha gesticulação fonética, dada com muitas outras na consciência global de meu corpo” (p. 246). Quando fala aqui no imaginado como "modalidades do meu ser no mundo", parece se referir a imaginação como uma modalidade da existência do ser. Além disso, no livro $O$ Transcendental e o Existente em MerleauPonty, Ferraz (2006) cita que "para Merleau-Ponty, a fala é uma modalidade existencial enformadora do mundo: “a denominação dos objetos não vem após o reconhecimento, ela é o próprio reconhecimento" (1997c, p. 207), defende” (p. 101). Mais adiante na obra Fenomenologia da Percepção, Merleau-Ponty (1945/2006) coloca o social como uma modalidade existencial importante:

\section{5}

Sobre o atual e o virtual como modalidade existencial, Merleau-Ponty cita a questão em uma nota de rodapé apontada no capítulo $A$ Espacialidade do Corpo Próprio e a Motricidade, na página 160, nota 30: “30. Goldstein \{Ueber die Abhàngigkeü, pp. 160 ss.\} contentase em dizer que o fundo do movimento abstrato é o corpo, e isso é verdade enquanto o corpo, no movimento abstrato, não é mais apenas o veículo e torna-se a meta do movimento. Todavia, mudando de função, ele muda também de modalidade existencial e passa do atual ao virtual".
O problema da modalidade existencial do social reúne aqui todos os problemas da transcendência. Quer se trate de meu corpo, do mundo natural, do passado, do nascimento ou da morte, a questão é sempre a de saber como posso ser aberto a fenômenos que me ultrapassam e que, todavia, só existem na medida em que os retomo e os vivo, como a presença a mim mesmo (Urprãsenz), que me define e condiciona toda presença alheia, é ao mesmo tempo uma des-presentação (Entgegenwàrtingung) e me lança fora de mim. (p. 487-488)

Esses excertos, assim, demonstram que MerleauPonty correlaciona "modalidade existencial" com corporeidade, expressão, imaginação, fala e social. Todos esses conceitos são compreendidos como modalidades da existência pelo filósofo e, portanto, são fundamentais e estruturantes da experiência vivida pelo ser no mundo. Entretanto, em nenhum momento o autor descreve a sua compreensão sobre modalidade existencial, como se esse conceito estivesse subentendido ao leitor em seu trabalho. Enfrentando a ausência de uma descrição específica em Merleau-Ponty, podemos recorrer às obras dos autores que influenciaram o seu trabalho em busca de uma resposta mais profunda. Neste caso, particularmente em Heidegger.

Face à necessidade de descrição e compreensão do conceito de modalidade existencial, temos em Ser e Tempo a seguinte observação de Heidegger (1927/2005) sobre a existência humana: “as características constitutivas da pre-sença são sempre modos possíveis de ser" (p. 78). A existência do ser se caracteriza por modos de abertura, nunca acabada, mas "sempre diante de uma possibilidade, um risco" (Ribeiro, 2000, p. 20). O que Heidegger (1927/2005) delineia aqui é que, possivelmente, quando pensamos em modalidades existenciais devemos compreendê-la como possibilidade. Para ele, "a possibilidade como existencial é a mais originária e última determinidade ontológica positiva do Dasein" (Heidegger, 1986 como citado em Reis, 2000, p. 279). Assim, "a pre-sença é sempre sua possibilidade" (Heidegger, 1927/2005, p. 78) e a sua concretização é diversa e pode variar historicamente: "A pre-sença possui em si própria diversas possibilidades de concretizar-se. As imposições e expressões de seu domínio podem variar historicamente" (Heidegger, 1927/2005, p. 182).

Pode-se observar na obra de Heidegger que, das possibilidades da existência, o Dasein pode ser um “eu” ou um "não-eu”, jogando-se na alienação ou na responsabilidade de si, autêntico ou inautêntico. Além disso, é co-presença, ser-com-no-mundo. Ainda, quando se refere aos modos de abertura que constituem o ser-no-mundo, o autor desvela os existenciais: a disposição, a compreensão, a 
interpretação e a linguagem. Todos esses existenciais estruturam a ontologia do Ser e aparecem como constitutivos do ser-aí ou pre-sença.

Entretanto, cabe esclarecer que, mesmo em Heidegger, a compreensão de "modalidade existencial” não é completamente possível. Reis (2000) afirma que Heidegger não desenvolveu esse conceito suficientemente, mas o apontou como um problema, iniciando sua discussão.

A medida da sua clarificação estende-se somente até a possibilidade no sentido da modalidade, da modalidade que é vista no contexto do enunciado e de sua certeza. Assim, a ideia de possibilidade é vista em conexão com atualidade e necessidade entendidas como determinações do ser, e, de fato, do ser da natureza em sentido amplo. $\mathrm{O}$ sentido de possibilidade e o tipo das estruturas de possibilidade que pertencem ao ser-aí enquanto tal nos estão totalmente fechados até hoje. (Heidegger, 1976 como citado em Reis, 2011, p. 274)

Aqui o próprio Heidegger afirma a impossibilidade de delimitar com profundidade esse conceito e destaca o sentido de "modalidade" correlacionado a "possibilidade”. Para além de outras acepções de possibilidade, compreenderemos sua noção existencial que envolve, segundo Reis (2000), pelo menos três considerações: “1) as determinações ou maneiras de ser do Dasein, 2) a sua qualificação ontológica última, enquanto capacidade de ser (Seinkönnen) e 3) o tornar algo possível (ermöglichen), que é propriamente aquilo que ser e sentido proporcionam" (p. 280).

Levando em consideração, então, essas três observações sobre possibilidade ou modalidade no seu sentido existencial, compreende-se que essa é determinante da experiência ontológica do ser-nomundo. Uma modalidade existencial caracteriza determinados modos de ser, diz da sua qualificação ontológica e possibilita sentidos. Ainda, é interessante ressaltar que a modalidade existencial dá origem a comportamentos que vinculam o ser com ou em relação a algo e possibilita a identidade existencial (Reis, 2011).

Assim sendo, a identidade existencial que resulta da individuação a partir de possibilidades é também a instância de individuação de comportamentos determinados, entendidos como relações submetidas a vínculos normativos. Por fim, as possibilidades existenciais desempenham um papel transcendental ou aletheiológico.

Essa última característica significa que o comportamento em relação a algo como algo determinado sempre é possível num contexto de comportamentos vinculados a possibilidades existenciais. Portanto, todo e qualquer ente que aparece como fenômeno sempre está identificado a partir de um contexto modal específico e complexo. (Reis, 2011, p. 275-276)

Se modalidade existencial, então, refere-se ao conceito de possibilidade existencial que Heidegger introduziu de modo a caracterizar a estrutura ontológica do ser-aí em modos de poder-ser que possibilitam sentidos e vinculação com o mundo, é compreensível que Merleau-Ponty em sua obra apresente o conceito correlacionando-o com análises profundas das características de corporeidade e intercorporeidade na existência humana. Corporeidade, como modalidade existencial, retrata um aspecto corpóreo da existência que implica estruturalmente em toda vivência humana, subjetiva e intersubjetiva. O corpo como pivô do mundo possibilita a existência, a instituição subjetiva e a relação profundamente entrelaçada do ser no mundo. E não só o corpo, mas a expressão, a fala e o social, todas são caracterizadas em Merleau-Ponty com o mesmo nível de importância na experiência, como modalidades da existência.

Desse modo, considerando os apontamentos realizados por Merleau-Ponty e Heidegger em torno da questão, pode-se observar que, a despeito do conceito não ter sido completamente discernido pela filosofia, sua relevância é identificável nas obras desses autores. Se para a ontologia do ser o entendimento de possibilidade é importante e designa ou caracteriza diversos outros conceitos utilizados em sua análise, é possível, então, repensar a questão de gênero, dialogando seus sentidos com a compreensão de modalidade existencial.

\section{Gênero como modalidade existencial}

Pensar sobre o gênero como modalidade existencial, é compreendê-lo como uma estrutura do ser humano, que se desdobra em possibilidades diversas de modo de ser particulares, que conduzem a um estilo próprio de cada pessoa, e que são desveladas pela intencionalidade desse ser, enquanto um "eu-posso" que está imbricado no mundo. Assim, retomamos em Merleau-Ponty (1945/2006) e os complementos conceituais ontológicos de Heidegger (1927/2005) para abrir novas possibilidades de compreensão sobre gênero.

A intencionalidade é o movimento de abertura do ser em direção ao mundo, uma intencionalidade do ser-corpo. Se existo é por que sou esse corpo intencional. Minha existência se dá no mundoda-vida, esse mundo que não é somente concreto, mas é o mundo de possibilidades onde o meu ser se situa, onde é/está situado. Assim, meu horizonte de possibilidades é situacional, espacial e temporal. O ser aqui não mais é definido em sua existência enquanto um “eu penso", mas um "eu posso”. E se 
pode é porque é encarnado, é um corpo intencional que se movimenta e se direciona ao mundo, em relação imbricada com esse. Esse horizonte da minha existência é diverso e é intersubjetivo/ intercorpóreo e circunscreve modos e relações complexas. Essa abertura existencial é caracterizada, como vimos, por possibilidades que facilitam modos de ser, de se vincular e se relacionar com os outros e o mundo. Uma das modalidades existenciais que é fundamental nas relações do ser com o mundo é o gênero. É só observarmos toda a história em torno das lutas (trans)feministas para identificar o gênero no centro de muitas disputas e, ao mesmo tempo, fundamental na identificação subjetiva do ser.

Para compreender mais sobre o gênero, recorreremos a uma analogia da experiência de gênero com o espectro da luz e as sensações por ela produzidas. A luz é em si a união de todas as cores, sua absorção e reflexão, o que a torna ao mesmo tempo todas as cores e nenhuma. A decomposição da luz por meio de um prisma explicita a diversidade que carrega quando direcionada para um anteparo onde possa ser visualizada e reconhecida. Gênero, aqui, refere-se ao espectro da luz. Como modalidade da existência, é ao mesmo tempo o tudo e o nada das possibilidades espectrais da experiência de gênero na existência. O prisma é o próprio ser, em sua corporeidade e particularidades perspectivas decorrentes das suas experiências temporais. O anteparo é a representação do mundo, do horizonte histórico-cultural e político onde o ser está situado, vive, expressa-se e experiencia relações.

O gênero, como modalidade existencial, descreve uma diversidade de possibilidades de identificação e de relações do ser no mundo. Como o corpo espectral da luz, é, então, todas as cores unidas em um só e ao mesmo tempo nenhuma, pois irradia/ reflete todas essas. O espectro que é o gênero só ganha corpo e possibilidade em um ser encarnado, o prisma que o decompõe de modo particular, instituindo uma identidade de gênero e expressão única, ainda que possa ter semelhanças generalizáveis de experiência com outrem. Aqui, o prisma é a própria carne, no sentindo merleau-pontyano, que sempre estará profundamente interligada com o mundo, o anteparo situacional onde é possível observar as expressões da identidade de gênero do ser e suas relações com a cultura, o social, o político e todas as suas complexidades históricas.

A despeito de realizar uma metáfora do gênero com o espectro da luz, ele nunca deve ser retirado a um plano metafísico. Sua instituição se dá em uma continuidade de atualizações possíveis desse espectro, na medida em que a experiência do ser encarnado possibilita sua ampliação no decorrer da história e das transformações das relações culturais e sociais. Assim, há 80 anos as únicas possibilidades aceitas no Brasil eram as configurações sociais normativas e binárias, ou seja, ser homem-masculino-pênis ou mulher-femininovagina. Hoje, as experiências intersexuais e transgêneras reconfiguram das mais variadas formas essas possibilidades de ser: transhomem-masculinovagina; transmulher-feminino-pênis; homemmasculino-intersexo; mulher-feminino-intersexo; queer-genderfluid-vagina; travesti-feminino-pênis, entre outras.

Nem sempre o que acontece com as transformações socioculturais dizem respeito a atualizações que ampliam as possibilidades da manifestação de diferentes identidades e expressões de gênero. Retrocessos políticos e morais históricos também implicam na restrição das experiências diversas. Não só na restrição, mas na patologização, negação e marginalização. Um exemplo claro disto é a marginalização de identidades transgêneras. Ainda podemos pensar nos retrocessos causados pelo processo de colonização. Algumas manifestações de gênero em tribos indígenas norte-americanas delineavam a possibilidade de até 5 identidades de gênero, algumas dessas expressões chamadas de two-spirit $^{6}$. A chegada dos colonizadores dizimou a potencialidade dessas identidades, que eram consideradas pecado e amaldiçoadas pelo cristianismo.

Todas essas experiências foram e são potências da modalidade existencial gênero, como um espectro amplo que possibilita a instituição de diversas identidades e expressões. Assim, este corpo que eu sou é, no campo das minhas experiências, tomado por uma identificação e expressão de gênero singular dentro dos espectros possíveis em relação ao complexo campo modal onde estou situado, podendo minha identidade inclusive ser restringida ou potencializada por ele. Nessa relação contínua vou adquirindo hábitos, integrando-os ao meu esquema corporal e gestual, assim como observado pelo trabalho de Flávia Silva (2017), desenhando meu estilo e sendo esse corpo que é, além de biológico e sexual, também social, afetivo, político, histórico-cultural e espacial-temporal.

\section{Possibilidades e Limites}

Como observado anteriormente, o movimento feminista desenvolveu a conceituação de gênero, primeiramente no sentido de colocar a mulher e o feminino em evidência situacional, demonstrando a inferiorização que sofre a mulher nas suas relações integrais no mundo em relação aos privilégios masculinos. A continuidade das discussões no feminismo levou à compreensão de que a experiência humana é fixada em dois polos, um feminino e um masculino, evidenciando uma disparidade de direitos femininos, o que foi de extrema importância para o desenvolvimento das relações sociais, políticas e existenciais da mulher.

6 Texto de Francine Oliveira, publicado no site Geledés: https:// www.geledes.org.br/antes-da-chegada-dos-cristaos-europeusnativos-norte-americanos-reconheciam-5-generos/ 
Mais recentemente, o descolamento do binarismo homem-masculino-pênis e mulher-feminino-vagina desvelou as possibilidades transgêneras de ser. Essas discussões caminham em várias perspectivas, que dialogam ou não entre si: gênero determinado pelos caracteres sexuais, como categoria histórica, construção social, cultural, étnica e política, como relações de poder, como situação ou ato performativo.

Se a noção de gênero aceita se fixar nos caracteres sexuais do corpo de uma pessoa, admitindo apenas duas possibilidades, como já citado (Bento, 2008), excluímos do horizonte de possibilidades experiências como transhomemmasculino-vagina, transmulher-feminino-pênis, homem-masculino-intersexo, mulher-femininointersexo, entre outras. Neste tipo de categorização, temos a evidência de um controle opressor sobre os corpos e sobre a potencialidade de significação do gênero, que limita a experiência, restringindo o movimento identitário e expressivo da pessoa. Decorre disso a patologização das identidades transgêneras, colocando-as às margens do binarismo normativo de gênero.

Quando Butler (1990/2003) se dispõe a retomar Merleau-Ponty e Beauvoir e evidenciar que o corpo é uma situação, uma ideia histórica, reafirma que o corpo é uma materialidade de significados, de gestos, mais do que matéria, mas materialização do conjunto de possibilidades que se realizam na experiência. Esse corpo traduz sentidos de gênero outros que não apenas os normatizados feminino e masculino. Mas demonstra performances de gênero variáveis, fluidas e que se transformam ao longo da história e da experiência da pessoa. Para Butler (1988/2018),

O gênero não é passivamente inscrito no corpo nem determinado pela natureza, a língua, o domínio simbólico ou a assoberbante história do patriarcado. O gênero é aquilo que se supõe, invariavelmente, sob coerção, diária e incessantemente, com angústia e prazer. Se esse ato contínuo, porém, é tomado como um fato natural ou linguístico, renuncia-se ao poder de ampliar o campo cultural corporal com performances subversivas de diversas classes. (p. 16)

Destaca-se a compreensão de que nem a natureza nem a inscrição cultural-social podem simplesmente invadir o corpo que, passivo, receberia seu gênero. Porém, compreender o gênero como uma identidade meramente instituída pela repetição de performances, encenadas no cotidiano, é negar um movimento passivo-ativo de tomada de sentido de gênero e de existência subjetiva pela pessoa, mais profundo do que apenas a instituição de atos performativos. As performances expressam a instituição de sentido de gênero, não são ela. Além disso, colocar atos performativos de pessoas trans como "subversivos" é deixar margem à reafirmação do seu estigma contra-normatizador ou sua situação marginal.

A possibilidade de compreender gênero como modalidade existencial abre espaço para considerar as identidades fora das amarras rígidas normativas, em sua diversidade e em sua real potência. Como conceito aberto e espectral, abrange as diversas configurações de identidades e expressões, mantendo a possibilidade de fluidez, os mais diversos sentidos que tomam o corpo e as transformações situacionais, espaço-temporais, onde se realizam em movimento contínuo.

Desse modo, considerar o conceito fenomenológico de modalidade existencial para refletir sobre as questões de gênero pode facilitar a validação das identidades potenciais que, historicamente, são marginalizadas e colocadas como subversivas, destoantes ou abjetas. A tentativa fenomenológica dessa abordagem reflexiva também incorpora as considerações já realizadas pela fenomenologia clássica e as autoras feministas contemporâneas: possibilidade existencial, corporeidade, situação, instituição, sentido, expressão e ato performativo.

Certamente, esse é um diálogo introdutório que se limita a uma nova provocação que carece ser aprofundada. Todos esses conceitos fenomenológicos necessitam ser revisitados e retomados com profundidade para que o diálogo entre esses fortaleçam uma nova possibilidade de abordarmos as questões de gênero, levando em consideração todas as contribuições das autoras da fenomenologia até aqui. Este é um trabalho, assim, que pretende ainda uma expansão, deixado aberto um novo campo a ser explorado.

\section{Considerações finais}

Discutir gênero é ainda um desafio e um campo aberto a possibilidades. De um ancoramento na implicância biológica dos genitais e caracteres sexuais até categorizações históricas e sociais, o conceito vem sendo repensado e debatido extensamente em diversas áreas. A fenomenologia feminista desenvolveu suas reflexões sobre a questão desde Beauvoir, que expôs a situação da mulher no mundo, até Butler, que subverteu as compreensões normativas da identidade de gênero, pintando com sua crítica quadros fluidos. As contribuições fenomenológicas possibilitaram ampliar a questão por meio de descrições e análises críticas e profundas de diversas experiências identitárias e múltiplas expressões. Ainda assim, novas discussões podem ser suscitadas quando pensamos no gênero como modalidade existencial.

A abertura de possibilidades existenciais em relação às manifestações do fenômeno gênero inclui os diversos modos de ser em um espectro amplo que 
se particulariza, instituindo-se na experiência do ser corporificado e em relação imbricada com a situação em que esse se encontra no mundo histórico, cultural, social, político e econômico que o envolve. O espectro gênero se institui pela experiência do ser encarnado, que como um prisma revela a expressão de sua identidade, refletida em relação a um anteparo situacional.

Desse modo, compreender gênero como modalidade existencial implica em acolher todas as possibilidades existenciais de identidade e expressão de gênero como potências que podem se manifestar das mais variadas formas, com maior ou menor fluidez. Alguns exemplos dessas potências, apenas de colocadas de modo correlativo e em relação à identidade, expressão e corpo, são: homem-masculino-pênis, mulher-feminino-vagina, transhomem-masculino-vagina, transmulherfeminino-pênis, queer-genderfluid-pênis, travestifeminino-intersexo, entre outras tantas potências.

Dentro dessa compreensão, reflexões járealizadas pelas autoras feministas podem se encontrar e dialogar, trazendo considerações sobre corporeidade, instituição, situação e atos performativos, bem como outros apontamentos sobre as experiências de gênero já desveladas pela fenomenologia. Esta proposta é uma abertura a novos aprofundamentos e diálogos sobre gênero, considerando-o como modalidade existencial e, assim, como um espectro de potências que se revelam na vivência corporificada e situada de uma pessoa.

\section{Referências}

Beauvoir, S. (1970a). O segundo sexo: Fatos e mitos. São Paulo: Difusão Europeia do Livro. (Obra original publicada em 1949).

Beauvoir, S. (1970b). O segundo sexo: A experiência vivida. São Paulo: Difusão Europeia do Livro. (Obra original publicada em 1949).

Bento, B. A. M. (2008). O que é transexualidade?. São Paulo: Brasiliense.

Blackwood, E. (2011). (Trans)gender: tomboi embodiment. In: Blackwood, E. (2011). A companion to the anthropology of the body and embodiment. Oxford: Blackwell Publishing Ltd., 207-222.

Butler, J. (2003). Problemas de gênero: feminismo e subversão da identidade. Rio de Janeiro: Civilização Brasileira. (Obra original publicada em 1990)

Butler, J. (2018). Os atos performativos e a constituição do gênero: um ensaio sobre fenomenologia e teoria feminista. Caderno de Leituras, 78, 1-16. (Obra original publicada em 1988). Recuperado de https:/chaodafeira.com/wp-content/ uploads/2018/06/caderno_de_leituras_n.78-final.pdf
Ferraz, M. S. A. (2006). O transcendental e o existente em Merleau-Ponty. São Paulo: Associação Editorial Humanitas: Fapesp.

Heidegger, M. (2005). Ser e Tempo (15ª ed.). Petrópolis: Vozes. (Obra original publicada em 1927).

Heinämaa, S. (2012). Sex, gender and embodiment. In Zahavi, D. (2012). The Oxford Handbook of Contemporary Phenomenology, 216-242. doi:10.1093/oxford$\mathrm{hb} / 9780199594900.013 .0012$

Lau, J. R. (2018). Transition as decreation: a transfeminist phenomenology of mixed/queer orientation. Graduate Journal of Social Science, 14(2), 24-43. Recuperado de http://gjss.org/sites/ default/files/issues/chapters/papers/GJSS\%20 Vol\%2014-2\%202\%20Lau.pdf

Mann, B. (2018). The difference of feminist phenomenology: the case of shame. Puncta Journal of Critical Phenomenology, 1(1), 41-73. doi: 10.31608/PJCP.v1i1.4

Merleau-Ponty, M. (2006). Fenomenologia da percepção (3a ed.) São Paulo: Fontes. (Obra original publicada em 1945).

Missaggia, J. (2015). Fenomenologia e feminismo: introdução e defesa de um diálogo fecundo. In Pacheco, J. (Org.). (2015). Mulher e filosofia: as relações de gênero no pensamento filosófico. Porto Alegre: Editora Fi, 157-179. Recuperado de http://historias.interativas.nom.br/aulas/wp-content/uploads/2017/03/mulherefilosofia.pdf

Oksala, J. (2006). A phenomenology of gender. Continental Philosophy Review, 39(3), 229-244. doi: 10.1007/s11007-006-9025-2.

Reis, R. R. (2000). Modalidade existencial e indicação formal: elementos para um conceito existencial de moral. Natureza Humana 2(2), 273-300. Recuperado de http://pepsic. bvsalud.org/scielo.php?script = sci_arttext\&pi$\mathrm{d}=\mathrm{S} 1517-24302000000200002$

Reis, R. R. (2011). Modalidades existenciais e negação. O que nos faz pensar 20(30), 273-288. Recuperado de http://www.oquenosfazpensar. fil.puc-rio.br/index.php/oqnfp/article/view/354

Ribeiro, E. C. (2000). Existência humana e responsabilidade: Definindo uma ética heideggeriana a partir de Ser e Tempo. (Dissertação de mestrado). Universidade Gama Filho, Rio de Janeiro, RJ, Brasil.

Salamon, G. (2011). The Sexual Schema: Transposition and Transgenderism. In Butler, J. Weed, E. (2011). The question of gender: Joan W. Scott's critical feminism (v. 4), 233-254. 
Scott, J. (1995, julho-dezembro). Gênero: Uma categoria útil de análise histórica. Educação \& Realidade, 20(2), 71-99. Recuperado de http:// www.seer.ufrgs.br/index.php/educacaoerealidade/article/view/71721

Silva, F. F. (2017). Errância corporal, gênero em trânsito. In Seminário Internacional Fazendo Gênero 11 \& 13th Women's Worlds Congress. Florianópolis, SC/Brasil. Recuperado de http://www.en.wwc2017.eventos. dype.com.br/resources/anais/1497923193_ARQUIVO_TrabalhocompletoFG2017.pdf

Young, I. M. (1980). Throwing like a girl: a phenomenology of feminine body comportment motility and spatiality. Human Studies 3(1), 137-156. doi: 10.1007/bf02331805
Matheo Bernardino (Orcid 0000-0003-2262-2356) é transhomem, Psicólogo Clínico, graduado em Psicologia pela FAE - Centro Universitário, e mestre em Psicologia Clínica pela Universidade Federal do Paraná. É pesquisador de temas relacionados a gênero, transmasculinidades e corporeidade. É voluntário no Transgrupo Marcela Prado, onde realiza acompanhamento psicológico de pessoas trans. É membro do Coletivo Apollo de pessoas transmasculinas e da Associação Nacional de Psicólogues Trans (ANP Trans). Email: matheo. bernardino@gmail.com

Recebido em 07.11.2019

Aceito em 21.07.2020 